\author{
А. Д. Гора, В. К. Кучинский, \\ Д. А. Стельмах, Т. А. Цивун
}

Государственное специализированное предприятие «Чернобыльская АЭС»

\section{Вопросы управления}

\section{знаниями}

\section{при снятии}

\section{с эксплуатации Чернобыльской АЭС}

На примере ГСП ЧАЭС показано, как длительность процесса снятия с эксплуатации, изменение рода деятельности предприятия и характеристик площадки сказываются на человеческих ресурсах предприятия и на системе управления знаниями. Основное внимание уделено изменению человеческих активов предприятия и интеллектуального потенциала персонала. Предложены математические зависимости, с помощью которых данные величины выражены в численном эквиваленте. Приведен анализ существующей ситуации, выполнены прогнозные оценки динамики указанных показателей, предложены пути обеспечения необходимого качества трудовых ресурсов в будущем.

\section{А. Д. Гора, В. К. Кучинський, Д. А. Стельмах, Т. А. Цівун}

Питання управління знаннями при знятті з експлуатації Чорнобильської АEC

На прикладі ДСП ЧАЕС показано, як тривалість процесу зняття з експлуатації, зміна роду діяльності підприємства та характеристик майданчика відображаються на людських ресурсах підприємства і на системі управління знаннями. Основну увагу приділено зміні людських активів підприємства й інтелектуального потенціалу персоналу. Запропоновано математичні залежності, за допомогою яких дані величини виражені в чисельному еквіваленті. Наведено аналіз існуючої ситуації, виконано прогнозні оцінки динаміки зазначених показників, запропоновано шляхи забезпечення необхідної якості трудових ресурсів у майбутньому. нятие с эксплуатации (СЭ) атомных электростанций - процесс достаточно продолжительный. Для Чернобыльской АЭС он начался в 2000 г. после досрочного останова последнего 3-го энергоблока [1]. В соответствии с «Программой снятия с эксплуатации Чернобыльской АЭС» [2] данный процесс закончится не ранее 2064 г., а если принять во внимание мероприятия по преобразованию объекта «Укрытие» в экологически безопасную систему [3], то вполне очевидно, что деятельность на площадке ЧАЭС может продолжаться около 100 лет и более.

В течение этого периода предполагается выполнение комплекса сложных организационно-технических мероприятий с привлечением неравномерного количества персонала, имеющего различный уровень квалификации. Чтобы обеспечить успешную реализацию запланированных работ в течение столь продолжительного времени, требуется эффективная система управления человеческим ресурсом.

В этом направлении, как правило, первоочередное внимание уделяется численности персонала. Уже существуют предварительные оценки потребности ГСП ЧАЭС в персонале на весь период СЭ, прогноз изменения численности персонала на основе анализа демографической ситуации, определена зависимость численности персонала от количества систем, остающихся в эксплуатации [4], [5], [6]. Тем не менее вопрос обеспечения персоналом необходимой компетенции в будущем остается открытым. Это несет в себе угрозу невыполнения намеченных планов несмотря на наличие необходимого количества персонала. Снизить данные риски и разработать компенсирующие мероприятия могут помочь исследования в области управления знаниями.

В рамках концепции развития предприятия принято выделять в качестве основных такие функциональные направления предприятия, как финансовое, производственное и кадровое. Интеллектуальный потенциал и человеческие активы обычно не рассматриваются как самостоятельные объекты управления, а распределяются по отдельным направлениям, тем самым приобретая второстепенное значение. Отчасти это связано с тем, что управление знаниями традиционно базируется на анализе неких условно-отчужденных процессов. При этом человек большинством подобных теорий «рассматривается как обработчик информации, а не ее создатель», в результате чего «организации подчас не обращают необходимого внимания на созидательный потенциал своих сотрудников» [7].

Однако мир не стоит на месте. Развитие общества, технологий, рано или поздно, неизбежно приведут к качественному скачку и в области теории и практики управления. В этой связи проблематика управления знаниями персонала представляется одним из возможных направлений дальнейшего прогресса.

Управление знаниями должно строиться в строгом соответствии со стратегией предприятия. Многолетний опыт эксплуатации ядерных объектов показывает, что управление ядерными знаниями является важной составляющей стратегии развития ядерной науки и техники [8], [9], [10] и неотъемлемой частью организационно-технических принципов обеспечения безопасности [11].

В области управления знаниями персонал предприятия играет ключевую роль. На это есть, как минимум, две основные причины: во-первых, персонал - основной 
носитель знаний, так как неформализованными остаются более 80 \% информации, которой располагает человек; вовторых, деятельность персонала является единственным способом использования полученных знаний на практике (процесс, определяющий ценность знаний).

Потеря или несоответствующее применение знаний, накопленных на Чернобыльской АЭС, могут иметь негативные последствия при достижении целей СЭ и преобразовании объекта «Укрытие» в экологически безопасную систему. К таким последствиям можно отнести низкое качество работ, медленное их выполнение, а также увеличение затрат. Длительный срок реализации этапов СЭ накладывает дополнительные требования к хранению опыта эксплуатации энергоблоков АЭС и передачи его новым поколениям работающих. На ранней стадии СЭ велика вероятность потери знаний, которые могут быть востребованы позже. Во избежание подобного необходима надёжная система сбора, передачи и архивирования данных.

Риск потери знаний возрастает со временем (с момента приобретения до применения). Причинами потери информация могут быть:

изношенные или морально устаревшие форматы хранения данных (бумажные документы, старые электронные форматы и т. д.). Этот риск можно отнести к потере так называемых явных знаний - тех, о которых мы знаем, можем их записать, сообщить другим и ввести в базу данных;

потери или ошибки, допущенные при передаче информации;

выход на пенсию квалифицированного и знающего объект персонала, а также его увольнение по социальным причинам, т. е. утечка персонала. Это ведет к потере неявных знаний, в состав которых входят мастерство, опыт, интуиция и т. п.

На основе управления знаниями возможно решение следующих основных задач:

повышение ценности человеческого ресурса;

рост интеллектуального потенциала;

повышение производительности умственного труда;

поддержка управленческих решений в стратегическом, инновационном, финансовом, технологическом и производственном вопросах.

Для отслеживания основных тенденций в области управления знаниями предприятия с целью выработки управляющих воздействий необходимо ввести измеряемые величины, которые позволили бы характеризовать существующее состояние и делать прогнозы на будущее. В качестве таких величин предлагается использовать человеческие активы предприятия и интеллектуальный потенциал персонала.

Человеческие активы - это совокупность коллективных знаний сотрудников, их творческих способностей, умений и личных качеств. В отличие от других активов, они нематериальны и не принадлежат предприятию, аккумулированы в самих людях и только они являются их носителями.

Понятия «человеческие активы предприятия» и «человеческие ресурсы» имеют отличие. Человеческие ресурсы - это потенциал, возможность, которая еще не реализована; это люди, каждый из которых имеет определенные знания и умения. Человеческие активы - это качества сотрудников.

В численном эквиваленте человеческие активы предприятия можно представить как интегральную величину, которая учитывает численность персонала ГСП ЧАЭС, его уровень образования, стаж и опыт работы, а также способность самостоятельно применять полученные знания и опыт в практической деятельности:

$$
P=\sum_{18}^{80} k S_{i} n_{i}\left[1-\left(\frac{t_{i}-35}{55-35}\right)^{2}\right],
$$

где $k-$ коэффициент, характеризующий уровень образования персонала на предприятии (за «1» принят уровень знаний, соответствующий высшему образованию); $S$ - стаж работы как представление полученных знаний, навыков, умения, опыта, компетенции; $n_{i}-$ количество персонала в $i$-й возрастной группе (от 18 до 80 лет); $t$ - возраст сотрудника $i$-й возрастной группы, лет; $1-\left(\frac{t_{i}-35}{55-35}\right)^{2}-$ зависимость, характеризующая способность самостоятельно применять на практике полученные знания и опыт: число 35 определяет оптимальный возраст для эффективного восприятия и применения знаний (данное значение принято исходя из верхнего предела, установленного для понятия «молодой специалист»); число 55 определяет возраст выхода на пенсию, когда предприятие теряет человека как носителя знаний (значение установлено исходя из среднего для персонала ГСП ЧАЭС возраста выхода на пенсию).

Зависимость, описывающая способность самостоятельно применять на практике полученные знания и опыт (рис. 1), принята согласно следуюшим положениям:

молодой человек в начале своей трудовой деятельности обладает высокой работоспособностью и способностью к усвоению знаний, однако у него отсутствует необходимый опыт и практические навыки;

в возрасте 35 лет (расцвет сил) сотрудник, приобретя необходимый опыт и умение самостоятельно применять полученные навыки, оставляет за собой высокую способность к восприятию новых знаний, а его физическая форма все ёще позволяет переносить высокие нагрузки, в том числе и психологические;

в предпенсионном возрасте люди обладают солидным багажом знаний и опыта, позволяющим им реально и прагматично оценивать ситуацию, однако их предыдущий опыт становится менее востребован, а способность к восприятию новых знаний снижается; к тому же слабая мотивация и проблемы со здоровьем не позволяют в полной

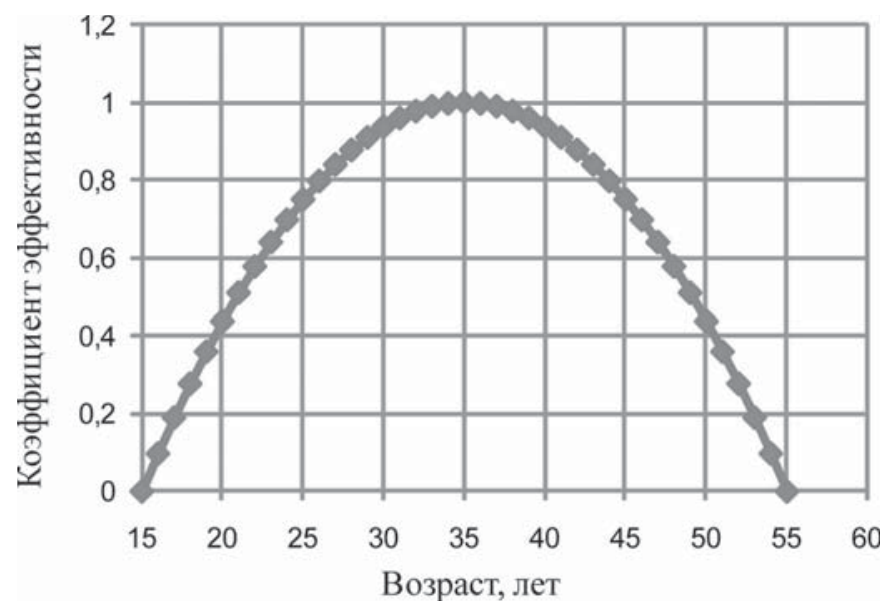

Рис. 1. Зависимость коэффициента эффективности восприятия и использования знаний от возраста сотрудника 
мере самостоятельно применять знания в практической деятельности;

с выходом человека на пенсию предприятие окончательно теряет в лице сотрудника человеческий капитал.

Применение данной зависимости с учетом фактического стажа работника дает в результате понятие «эффективный стаж». В качестве примера на рис. 2 показана зависимость эффективного стажа от возраста сотрудника, который начал свою трудовую деятельность в 18 лет, максимальную отдачу от него можно ожидать в возрасте от 35 до 48 лет.

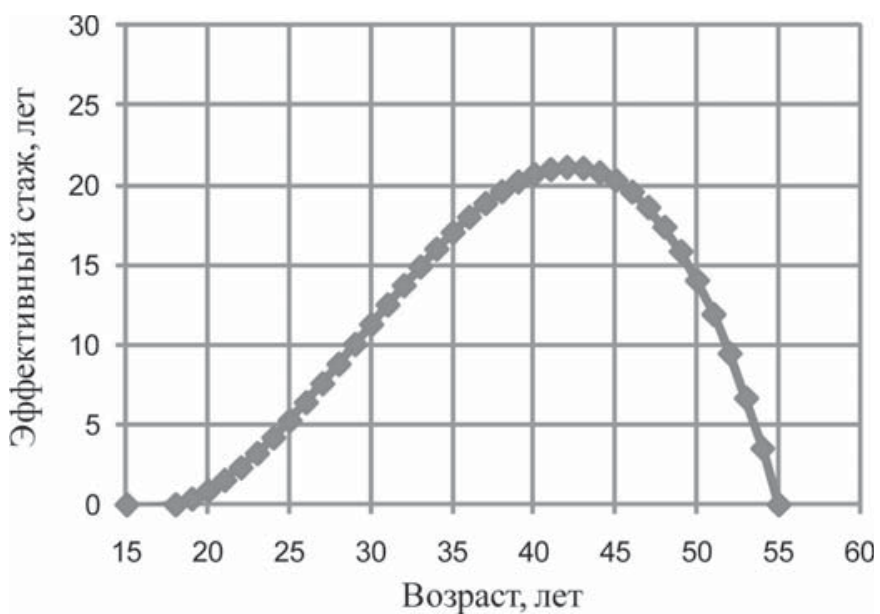

Рис. 2. Зависимость эффективного стажа от возраста сотрудника

С использованием предложенной модели выполнены прогнозные оценки изменения человеческих активов ГСП ЧАЭС в период снятия с эксплуатации для трёх вариантов обеспечения предприятия персоналом (рис. 3):

без приема персонала на работу;

с поддержанием существующей численности персонала ГСП ЧАЭС:

с фиксированным приемом персонала (по 100 человек в год).

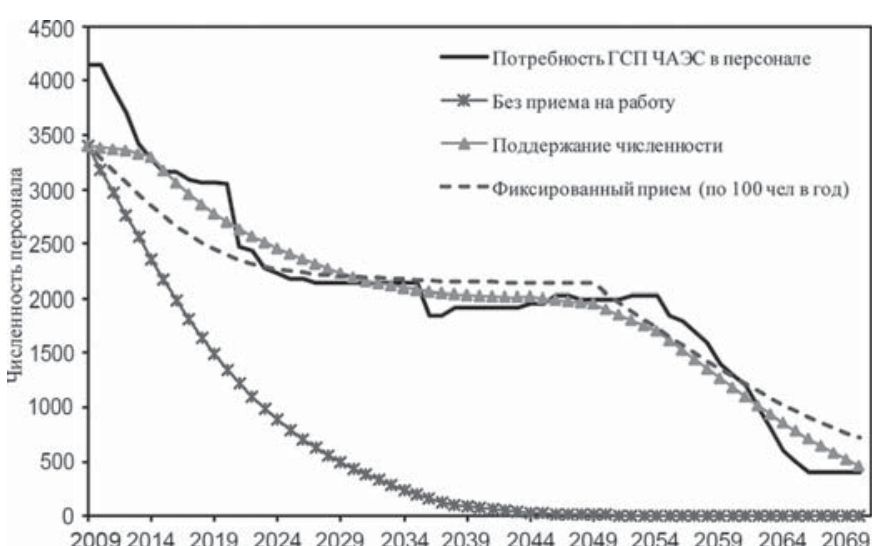

Рис. 3. Обеспечение ГСП ЧАЭС персоналом

Полученные результаты (рис. 4, 5, 6) свидетельствуют о том, что для любого из рассмотренных вариантов очевидно значительное снижение человеческих активов ГСП ЧАЭС (рис. 7) - от 17 до $30 \%$ (в зависимости от варианта) - в течение ближайших 5 лет.

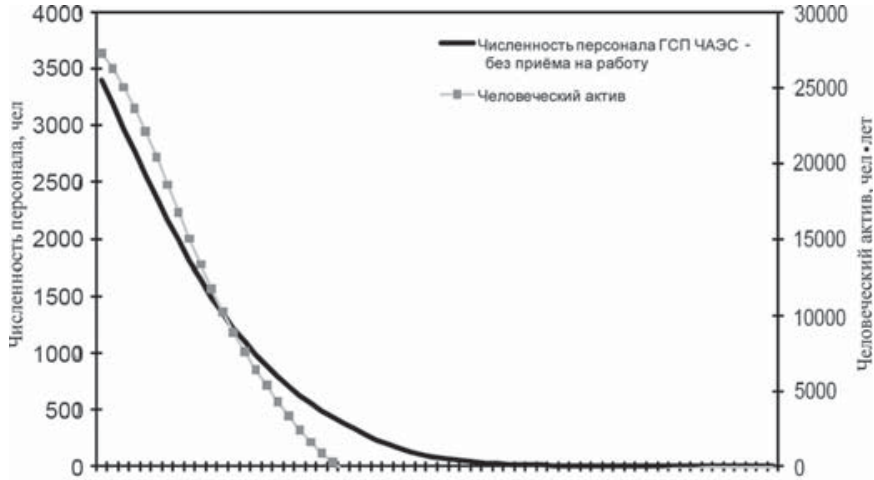

2009201420192024202920342039204420492054205920642069

Рис. 4. Динамика изменения человеческого актива ГСП ЧАЭС без приема персонала на работу

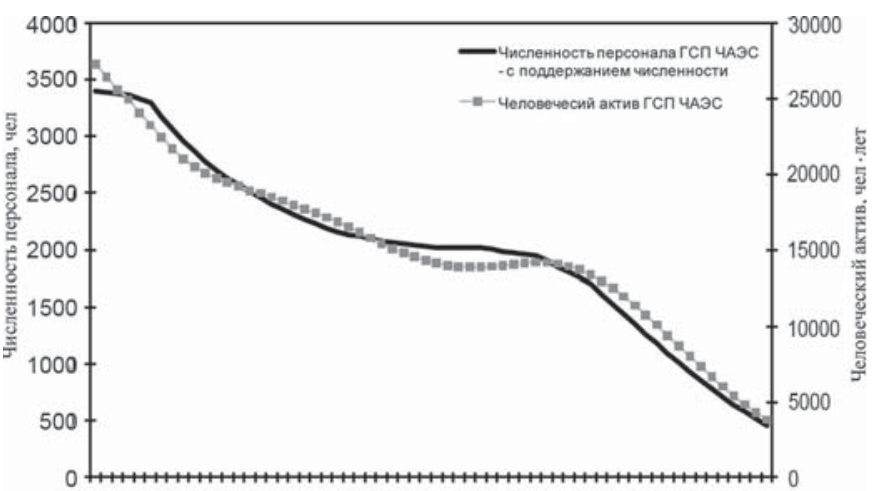

2009201420192024202920342039204420492054205920642069

Рис. 5. Динамика изменения человеческого актива ГСП ЧАЭС с сохранением численности персонала

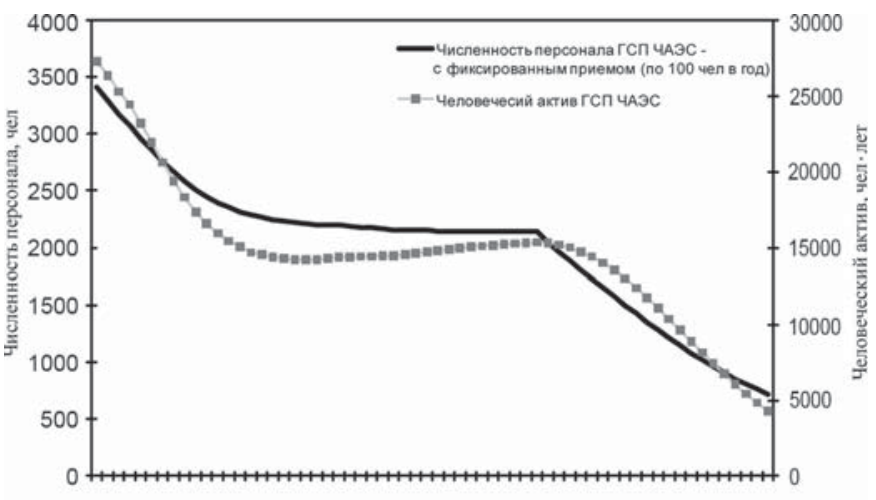

2009201420192024202920342039204420492054205920642069

Рис. 6. Динамика изменения человеческого актива ГСП ЧАЭС с фиксированным приемом персонала (по 100 человек в год)

Для смягчения возможных последствий необходимо уделить должное внимание систематизации и документированию знаний. Эта задача связана с большими объемами информации, поэтому должна стать составляющей политики развития информационных технологий ГСП ЧАЭС. Поскольку основным носителем знаний, обладающим возможностью их использования, остается человек, задача по сохранению знаний и, соответственно, человеческих активов в основном ложится на такое направление деятельности 


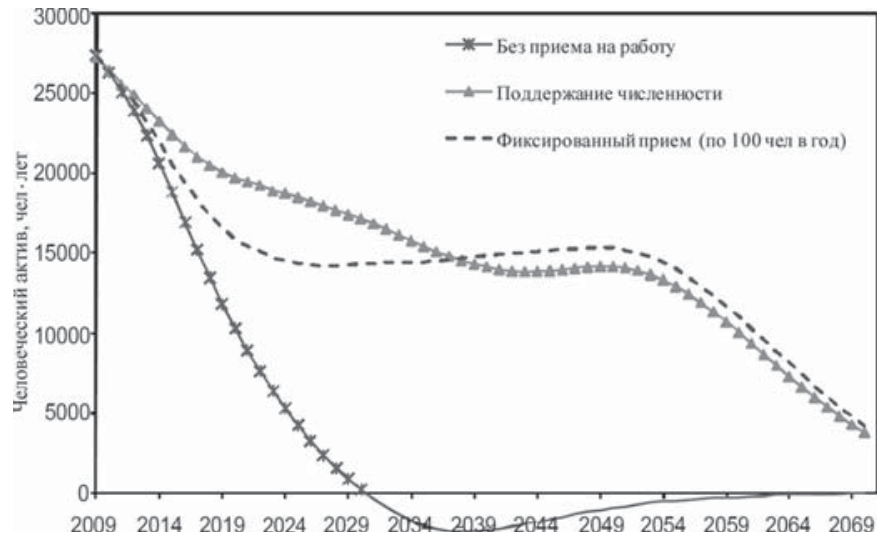

Рис. 7. Варианты изменения человеческого актива ГСП ЧАЭС

предприятия, как развитие персонала. Это становится более очевидным при анализе причин уменышения человеческих активов.

Ситуация с неизбежным уменьшением человеческих активов ГСП ЧАЭС обусловлена двумя основными факторами: уменьшением численности персонала предприятия и постепенным сокращением среднего по ГСП ЧАЭС эффективного стажа. Даже при реализации политики по сохранению численности персонала ГСП ЧАЭС (см. рис. 5), в связи с выходом на пенсию и текучестью кадров будет высвобождаться наиболее опытный персонал, а новым людям, которые придут им на смену, понадобится время, чтобы получить аналогичные навыки, знания и квалификацию.

Для ГСП ЧАЭС ситуация усугубляется еще тем, что после ликвидации аварии на 4-м блоке (1986 г.) было заменено более $80 \%$ персонала станции (рис. 8).

В течение короткого промежутка времени было принято большое количество персонала примерно одного возраста - 20 лет, которые в ближайшие семь лет достигнут пенсионного возраста и составят основную долю убыли персонала (рис. 9).

Сложившуюся ситуацию с уменьшением эффективного стажа персонала ГСП ЧАЭС лучшим образом раскрывает такой показатель, как интеллектуальный потенциал.

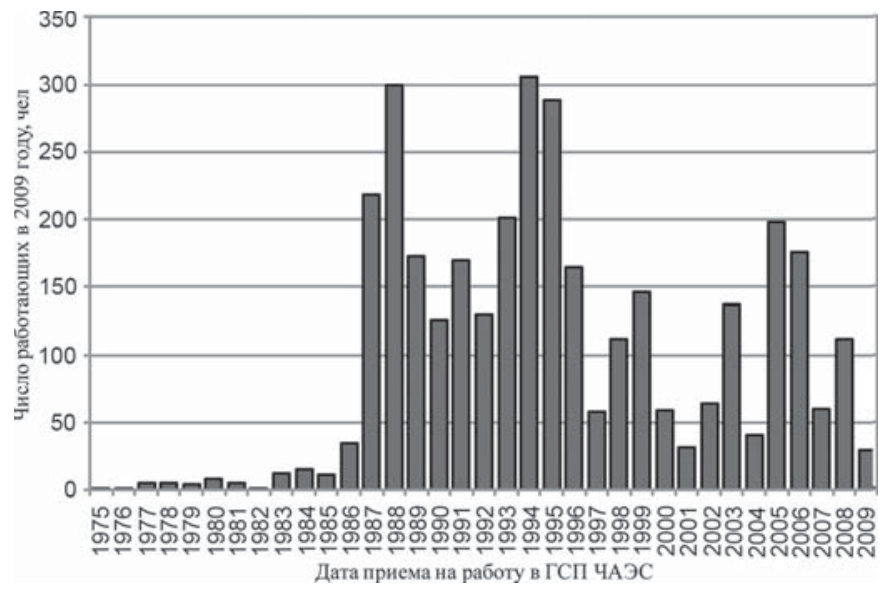

Рис. 8. Распределение персонала ГСП ЧАЭС (из числа работающих в 2009 г.) по дате приема на предприятие

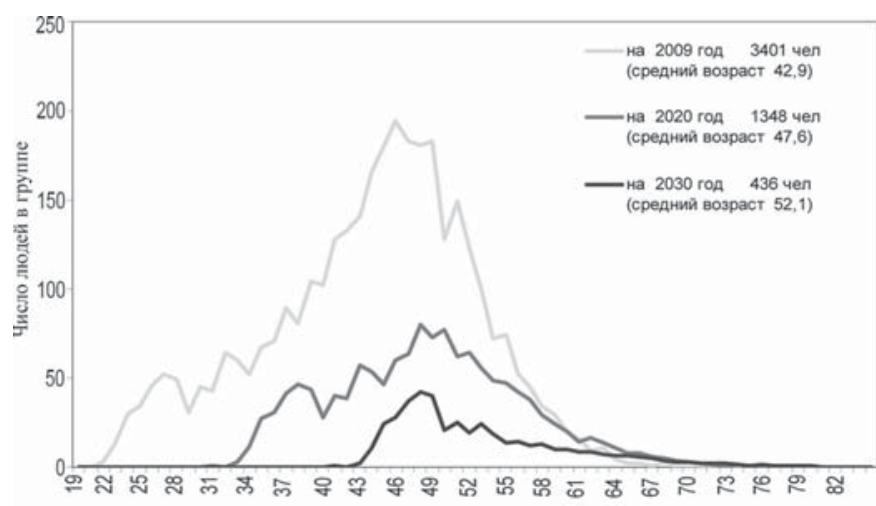

Рис. 9. Изменение возраста персонала ГСП ЧАЭС по состоянию на 2009 г.

Интеллектуальный потенциал - величина, характеризующая человеческий капитал, которым обладают сотрудники предприятия, - дает представление о качестве персонала ГСП ЧАЭС, его компетентности; выражает способность среднестатистического работника использовать на практике накопленные знания и опыт. Критериями оценки интеллектуального потенциала личности, представляющими интерес для организации, являются образование, профессиональная квалификация, связанные с работой знания, профессиональные наклонности и связанные с работой умения [12].

Интеллектуальный потенциал среднестатистического работника ГСП ЧАЭС можно представить как отношение человеческих активов предприятия к его численности. Для сравнения величина интеллектуального потенциала рассматривается в отношении к 2009 г.:

$$
I=\left(P_{y} / N_{y}\right) /\left(P_{2009} / N_{2009}\right),
$$

где $P_{y}-$ размер человеческих активов в $y$-м году; $N_{y}-$ численность персонала в $y$-м году; $P_{2009}-$ размер человеческих активов в 2009 г.; $N_{2009}-$ численность персонала в 2009 г.

Результаты прогнозных оценок изменения интеллектуального потенциала персонала ГСП ЧАЭС (рис. 10) показывают: несмотря на то, что в ближайшие два-три года он будет оставаться на приемлемом уровне, в среднесрочной и долгосрочной перспективе предприятие может столкнуться с недостаточной компетенцией персонала по сравнению с 2009 г.

Если принять за критический уровень снижение интеллектуального потенциала персонала на $20 \%$ по сравнению с 2009 г., то уже через 5-7 лет можно ожидать увеличения вероятности отказов из-за ошибок персонала. Исключение - вариант без приема персонала на работу. В этом случае снижение интеллектуального потенциала персонала из числа оставшихся сотрудников не будет таким стремительным (первое время возможен даже рост). Однако через 10 лет, когда средний возраст персонала станции достигнет 50 лет, процесс станет необратимым, даже если возобновить прием персонала (рис. 11). При этом человеческие активы будут снижаться с наибольшей скоростью (рис. 4). Данный пример - хорошая иллюстрация понятия «разрыв поколений».

Как видно по динамике изменения интеллектуального потенциала, управление знаниями - процесс достаточно 


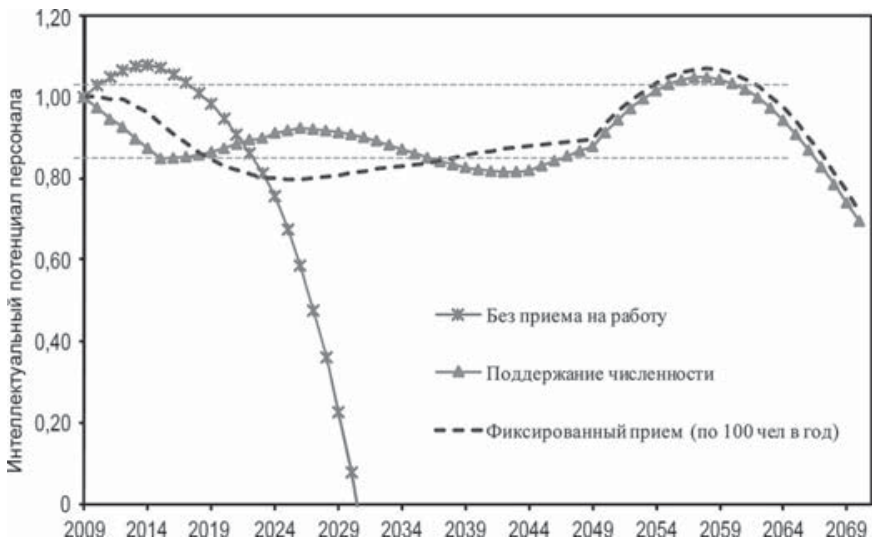

Рис. 10. Оценка изменения интеллектуального потенциала персонала ГСП ЧАЭС

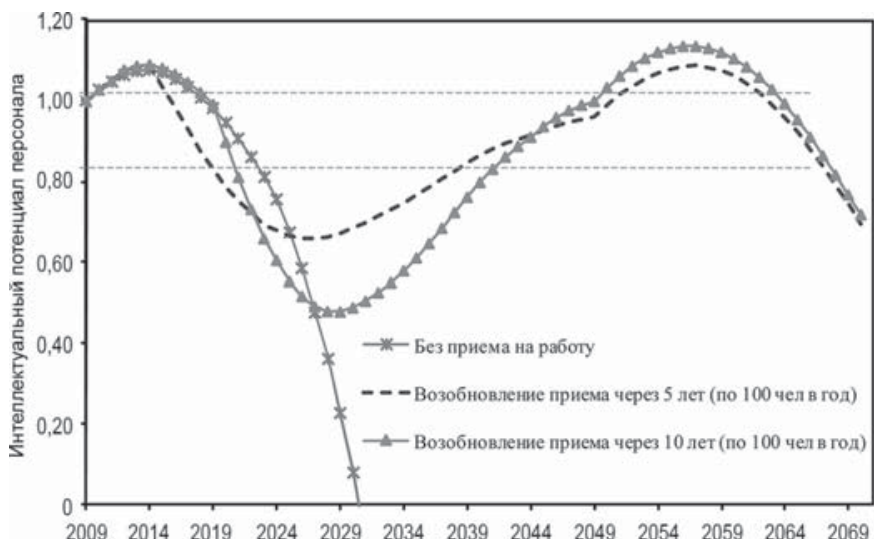

Рис. 11. Изменение интеллектуального потенциала персонала ГСП ЧАЭС без приема персонала на работу

инертный и, как уже упоминалось выше, зависит от эффективного стажа персонала ГСП ЧАЭС.

Смена кадров порождает проблему «потери знаний». Результаты такой потери могут быть просто катастрофическими: повторяющиеся ошибки и «изобретение велосипеда» существенно снизят качество работы, замедлят, например, процесс разработки новых проектов. После ухода на пенсию персонала со стажем потребуется значительное время на то, чтобы новые сотрудники приобрели необходимые навыки и опыт. Более того, достигнуть существующего уровня без специальных мероприятий не удастся. Организация может оказаться в тупике при возникновении новой проблемы [13].

Одной из специальных мер может быть прием на предприятие людей с опытом работы в атомной энергетике, что и было сделано на Чернобыльской АЭС после 1986 г., когда были приглашены специалисты со всего СССР. В настоящее время ГСП ЧАЭС не располагает такими возможностями. Единственным способом для Чернобыльской АЭС выйти из сложившейся ситуации остается развитие собственного персонала: обучение является ключевым инструментом для передачи знаний как работникам, непосредственно участвующим в реализации проектов, так и персоналу других заинтересованных организаций. Эта возможность учитывается введением в формулу расчёта человеческих активов (1) коэффициента, характеризую-

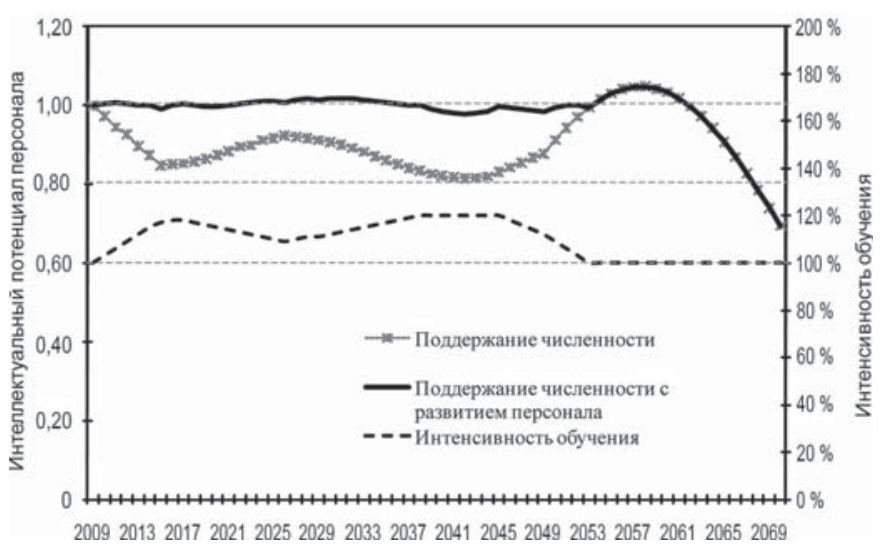

Рис. 12. Динамика интеллектуального потенциала персонала ГСП ЧАЭС с увеличением интенсивности обучения

щего уровень образования персонала на предприятии $(k)$. Развивая компетенцию персонала, ГСП ЧАЭС в состоянии обеспечить необходимый уровень интеллектуального потенциала (рис. 12).

Для решения поставленной задачи необходимо делать акцент на развитие персонала в целях повышения его квалификации. В первую очередь это касается вновь принятого персонала, который имеет минимальный производственный стаж. В данном случае особую роль должна сыграть совместная работа учебно-тренировочного центра с отделом развития персонала, которые, исходя из перспективных потребностей предприятия, будут заблаговременно планировать, а также осуществлять подбор и подготовку персонала.

Развитие персонала должно быть основано на систематическом обучении персонала в соответствии со стратегиями предприятия. Также необходимо повысить статус наставничества, что поможет сохранить накопленные знания и улучшить качество подготовки персонала. Все эти мероприятия должны способствовать становлению ГСП ЧАЭС как самообучающейся организации и решить проблему сохранения человеческих активов предприятия.

\section{Выводы}

Как показывает проведенный анализ, кроме общих проблем, связанных с недостаточной численностью персонала вследствие сложившейся демографической ситуации [6], ГСП ЧАЭС в перспективе столкнется с вопросами обеспечения необходимого качества человеческих ресурсов. В основном это связано с тем, что в течение 5 лет треть персонала станции будет обновлена. Сложившаяся ситуация приведет, во-первых, к уменьшению человеческих активов предприятия в ближайшие 5 лет на 17-30\%; вовторых, к снижению интеллектуального потенциала персонала станции (приблизительно на 20 \%).

Сокращение человеческих активов предприятия и интеллектуального потенциала персонала может отрицательно сказаться на способности ГСП ЧАЭС решать сложные и масштабные задачи, а также на качестве выполняемых работ в будущем; может возрасти вероятность отказов изза ошибок персонала, что в общем счете может отразиться на безопасности. 
Необходима планомерная система обучения и развития персонала, ориентированная на становление ГСП ЧАЭС как самообучающейся организации, - одно из немногих направлений деятельности, решающее большинство поставленных выше задач по управлению человеческими активами ГСП ЧАЭС.

С точки зрения управления знаниями очень важно иметь возможность оценить сложившуюся ситуацию и выполнить прогнозные оценки. Это во многом способствует своевременному планированию компенсирующих мероприятий и снижению рисков невыполнения предприятием поставленных задач из-за неготовности персонала. Предложенные ГСП ЧАЭС подходы к оценке человеческих активов предприятия и интеллектуального потенциала персонала могут оказаться полезными и для других организаций, которые сталкиваются со схожими проблемами.

\section{Список литературы}

1. Про дострокове припинення експлуатації енергоблока № 3 та остаточне закриття Чорнобильської АЕС: Постанова КМУ № 598 від 29 березня 2000 р.

2. Программа снятия с эксплуатации Чернобыльской АЭС / ГСП ЧАЭС. - Славутич, 2006. - 198 с.

3. Стратегія перетворення об’єкта «Укриття» / ГСП ЧАЭС. K., 2001. $-18 \mathrm{c}$.
4. Концепция управления человеческим ресурсом ГСП ЧАЭС на период до 2020 года / ГСП ЧАЭС. - Славутич, 2006. - 64 с.

5. Анализ обеспечения ГСП ЧАЭС человеческими ресурсами ГСП ЧАЭС. - Славутич, 2009. - 84 с.

6. Гора А. Д. Зависимость численности персонала ГСП ЧАЭС от количества систем, находящихся в эксплуатации, и возраста персонала / А. Д. Гора, В. К. Кучинский, В. М. Гавриш и др.// Ядерна та радіаційна безпека. - 2008. - № 2. - С. 9-17.

7. Нонака И. Такеучи Х. Компания - создатель знания. Зарождение и развитие инноваций в японских фирмах. - М.: ЗАО «Олимп-Бизнес», 2003.

8. Transition from Operation to Decommissioning of Nuclear Installations: Technical Report Series No. 420, IAEA. - Vienna, 2004. $-226 \mathrm{p}$.

9. Planning, managing and organizing the decommissioning of nuclear facilities: lessons learnd: Technical Report Series No. 1394, IAEA. - Vienna, 2004. - $107 \mathrm{p}$.

10. Decommissioning of Nuclear Facilities: Training and Human Resource Considerations: Technical Report Series No. NG-T-2.3, IAEA. - Vienna, 2008. - $147 \mathrm{p}$.

11. НП 306.2.141-2008. Загальні положення безпеки атомних станцій / Держатомрегулювання України. - К., 2008. - 78 с.

12. Багов В.П. Управление интеллектуальным капиталом: Учеб. пособие/ В. П. Багов, Е. Н. Селезнёв, В. С. Ступаков. - М.: ИД «Камерон», 2006. - 248 с.

13. Лазарев C. B. Внедрение систем управления знаниями в энергетике// Энергетик. - 2009. - № 2. - С. 16-19.

Надійшла до редакції 03.02.2010. 